\title{
Wh-Questions in Malagasy
}

\author{
Eric Potsdam \\ University of Florida
}

\section{Introduction}

Wh-questions in Malagasy consist of a clause-initial wh-phrase followed by an invariant particle and then the remainder of the clause. This paper considers the structural analysis of Malagasy wh-questions and argues for a biclausal cleft analysis in which the initial wh-phrase is a predicate and the remaining material is a headless relative in subject position. The paper is organized as follows: Section 2 introduces some basic facts about Malagasy clause structure and wh-questions. Section 3 lays out two competing structural analyses of wh-questions: the cleft analysis and a fronting analysis in which Malagasy wh-questions are derived by wh-movement. Section 4 introduces various evidence in favor of the pseudocleft analysis and against the fronting analysis. Section 5 concludes.

\section{Malagasy Syntax and Wh-Questions}

Malagasy is an Austronesian language spoken on the island of Madagascar. It is well-known for having basic VOS word order, (1a), and a robust voice system which advances thematically diverse elements to the clause-final subject position. Corresponding to the active sentence in (1a), the PASSIVE sentence in (1b) has the direct object as the clause-final subject and the CIRCUMSTANTIAL sentence in (1c) has an oblique element as its subject. Note that the agent in non-active clauses appears immediately following the verb. ${ }^{1,2}$
a. n-i-vidy ny akoho i Bao
PAST-ACT-buy the chicken Bao
'Bao bought the chicken.'
b. no-vidi-n' i Bao ny akoho
PAST-buy-PASS Bao the chicken
'The chicken was bought by Bao.'
b. n-i-vidi-anan' i Bao ny akoho i Soa
PAST-ACT-buy-CIRC Bao the chicken Soa
'Soa was bought a chicken by Bao.'
ACTIVE
PASSIVE

For concreteness I adopt structures from Guilfoyle, Hung, and Travis 1992. In active clauses, the clause-final subject occupies a right specifier of IP and the verb raises to I•, yielding VOS word order, (2a). PredP is a projection in whose specifier the external argument is introduced (Bowers 1993, see also Chomsky's (1995) vP). For non-active clauses, the immediately post-verbal agent is in the predicate-internal subject position, spec,Pred, with the clause-final subject again in spec,I, (2b). 
(2) a.

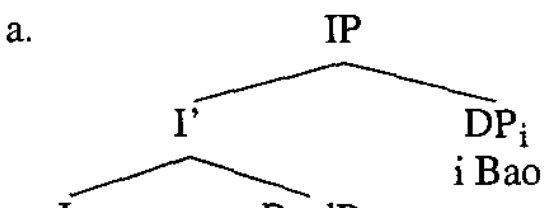

b.<smiles>CC(C)[Pb]C(=O)O</smiles>

nividy $_{\mathrm{k}}$ 'buy'

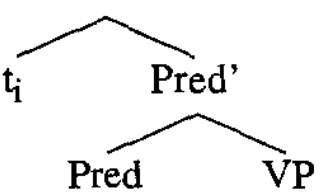

$t_{k}$<smiles>[Y]C[Pb]</smiles>

$t_{\mathrm{k}}$

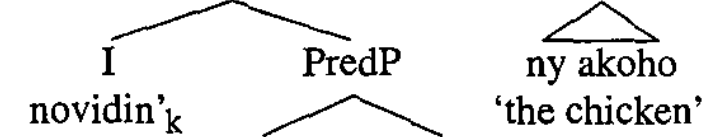
'buy.PAss' DP

cho

'the chicken'

Descriptively, wh-questions in Malagasy are formed by preposing the whphrase and following it immediately with the particle no (glossed as PRT) and then the remainder of the clause:

(3) a. iza no nividy ny akoho? who PRT buy.ACT the chicken 'Who bought the chicken?'

b. inona no novidin' i Bao? what PRT buy.PASS Bao

'What was bought by Bao?'

It is widely cited that only subjects can be questioned with this strategy (Keenan 1976, 1995, MacLaughlin 1995, Paul 2000, 2002, Pearson 2001, Sabel 2002, and others). Non-subject questions are ungrammatical:

(4)
a. *inona no nividy i Bao?
what PRT
buy.ACT Bao
('What did Bao buy?')
b. *iza no novidina ny akoho?
who PRT buy.PASS the chicken

('Who was the chicken bought by?')

An exception to this claim is that some adjuncts, including temporal, locative, and instrumental adverbials, can be questioned without first advancing to subject position (Keenan 1976, Rabenilaina 1998, Paul 2000, 2001, 2002, Pearson 2001, Sabel 2002, and others). (5) shows that a question with where is compatible with any verbal voice form. Only in the example with circumstantial voice, $(5 \mathrm{c})$, does the adverbial correspond to a subject. 
(5) a. taiza no nanafina ny lakileko ny zaza where PRT hide.ACT the key.1SG the child

b. taiza no nafenin' ny zaza ny lakileko where PRT hide.PASS the child the key.1SG

c. taiza no nanafenan' ny zaza ny lakileko where PRT hide.cIRC the child the key.1SG 'Where did the child hide my key?'

This restriction, that only subjects and some adjuncts can be extracted, will be important as a descriptive generalization in discussions to follow (see MacLaughlin 1995, Sabel 2002, Paul 2002, and Pearson, to appear for possible analyses of the restriction).

\section{Two Hypotheses}

This section introduces two structural analyses of Malagasy wh-questions from the literature. The FRONTING ANALYSIS (Sabel 2002, 2003) likens the structure of whquestions in Malagasy to that of wh-movement structures in better studied languages. Wh-questions, such as (6) below, resemble English wh-fronting examples and can be assigned a familiar structure, (7a). The wh-phrase moves to spec, $\mathrm{C}$ and $n o$ is question complementizer in $\mathrm{C}^{\circ}$.

$$
\begin{aligned}
& \text { iza no nihomehy? } \\
& \text { who PRT laugh.ACT } \\
& \text { 'Who laughed?' }
\end{aligned}
$$

$$
\text { FRONTING ANALYSIS }
$$

(7)

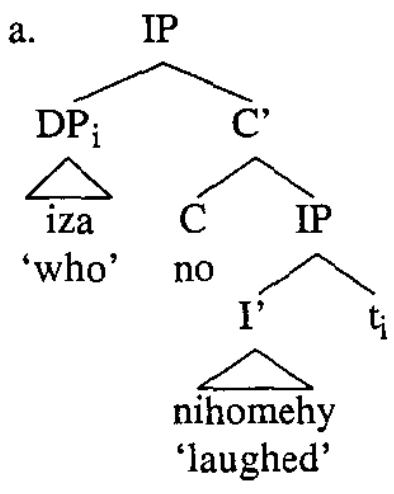

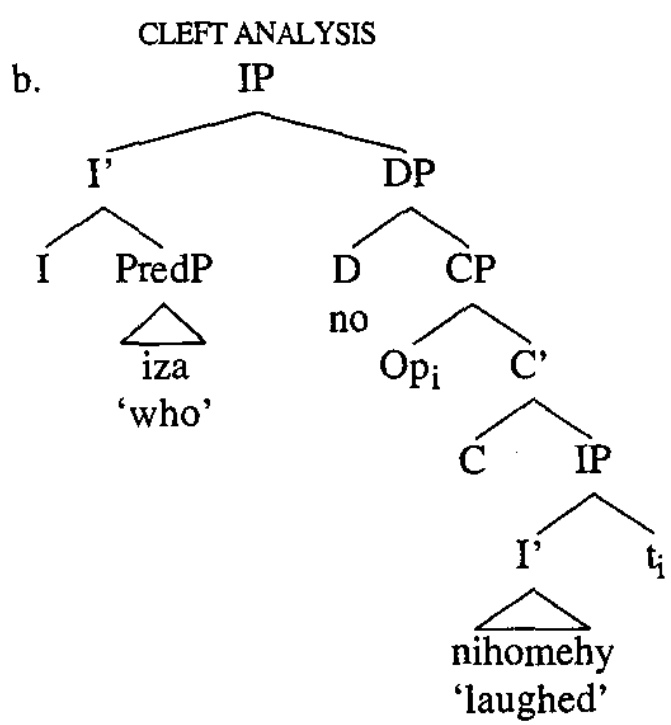

The CLEFT ANALYSIS to be defended here builds on proposals in Dahl 1986, Pearson 1996, Paul 2001, 2003b, and others. Under the cleft analysis, wh-questions are pseudocleft structures in which the wh-phrase is a non-verbal predicate and the subject is a headless relative clause involving internal movement of a null operator, 
Op. The wh-question in (6) is assigned the structure in (7b). For concreteness, I take the focus particle no under the cleft analysis to be a determiner and the relative clause its complement, as shown. Paul 2001 points out that some related Austronesian languages are also argued to employ a pseudocleft structure for questions, for example, Palauan (Georgopoulos 1991), Tagalog, and Seediq (Aldridge 2002).

\section{Argumentation Against the Fronting Analysis}

This section provides evidence in favor of the pseudocleft analysis from parallels with a cleft focus construction, word order facts, and multiple wh-questions.

\section{1 parallels with the focus construction}

Malagasy has a focus construction illustrated in (8) that is formally similar to whquestions. Dahl 1986 first proposed that this focus construction is a kind of cleft and Paul 2001, 2003a develops this idea, assigning (8a) the pseudocleft structure in (9). The focused element is the predicate of the clause and the subject is a headless relative clause.
a. Rasoa no nihomehy
Rasoa PRT laugh.ACT
'It was Rasoa who laughed'
b. ny mofo no novidin- dRasoa
the bread PRT buy.PASS Rasoa
'It was the bread that was bought by Rasoa'

(9)

$$
\begin{aligned}
& \text { [ [ } \text { predicate }_{\text {Rasoa }} \text { ] [subject/headless relative clause no } O p_{i} \text { nihomehy } t_{i} \text { ] ] } \\
& \text { Rasoa PRT laughed }
\end{aligned}
$$

There are a number of non-trivial parallels between wh-questions and the focus construction, which suggest that they should receive the same structural analysis. First, both are formed by preposing a constituent and following it immediately with the particle no. Second, the two constructions have a similar focus interpretation of the initial XP. Wh-phrases indicate a request for new information in the same way that focused XPs supply new information. Third, the two constructions are subject to the same extraction restriction, that only subjects and adjuncts can be extracted. In (10), adjuncts are focused regardless of the voice of the verb (compare to the whquestions in (5)). In (11), we see the ungrammaticality that results from focusing a non-subject argument (compare (4)).
(10)
ao ambanin'
ny fandriana no
there under
the bed
no nanafina
PRT hide.ACT
ny lakile ny zaza
b. ao ambanin'
ny fandriana no
there under
the bed
PRT hide.PASS
the key the child
ny zaza ny lakile
the child the key 
c. ao ambanin' ny fandriana no nanafenan' ny zaza ny lakile there under the bed PRT hide.CIRC the child the key

'It's under the bed that the child hid my key'

(11) a. *ny mofo no nividy i Bao

the bread PRT buy.ACT Bao

('It's the bread that Bao bought')

b. *Rabe no novidina ny akoho?

Rabe PRT buy.PASS the chicken

('It's Rabe that the chicken was bought by')

Such similarities are perhaps unexpected under the fronting analysis in which the two constructions have rather different derivations.

\section{2 predicational properties of the wh-phrase}

One distinction between the two analyses concerns the characterization of the initial wh-phrase. Under the pseudocleft analysis, it is a predicate, while under the fronting analysis, it is a preposed constituent. We can thus differentiate the two analyses by seeing whether a fronted wh-phrase has properties characteristic of predicates or not. This subsection demonstrates that the position of predicate-related particles treats initial wh-phrases as predicates, not as fronted elements.

Malagasy has a number of particles that immediately follow the predicate in ordinary clauses. These post-predicate particles include the quantifiers daholo 'all' and avy 'each' (Keenan 1976, 1995), the exclamative particle anie (Keenan 1976, 1995), and VP adverbs such as foana 'always' (Pearson 1998, Rackowski 1998). There is abundant evidence that the verb and its complements constitute a predicate to the exclusion of the subject in Malagasy (Keenan 1976, 1995) and in VOS clauses these elements appear immediately after the predicate and before the subject but not elsewhere:

$$
\begin{aligned}
& \text { a. nihinana vary (daholo) ny vahiny }(* \text { daholo) } \\
& \text { eat.ACT vary all the guest all } \\
& \text { 'All the guests ate rice' } \\
& \text { b. manapaka bozaka (anie) Rasoa (*anie) } \\
& \text { cut.ACT grass EXCL Rasoa EXCL } \\
& \text { 'Rasoa is really cutting the grass!' } \\
& \text { c. mihomehy (foana) Rasoa (*foana) } \\
& \text { laugh.ACT always Rasoa always } \\
& \text { 'Rasoa is always laughing' }
\end{aligned}
$$

For concreteness, I assume that these particles right adjoin to PredP. This correctly places them between the object and the subject in VOS clauses. The two analyses under consideration make different predictions about where these particles will appear in wh-questions. As shown in (13a), the cleft analysis places them immediately after the wh-phrase. The fronting analysis, in contrast, does not and predicts that they must be lower in the structure, near the end of the clause, (13b). 
(13) a.

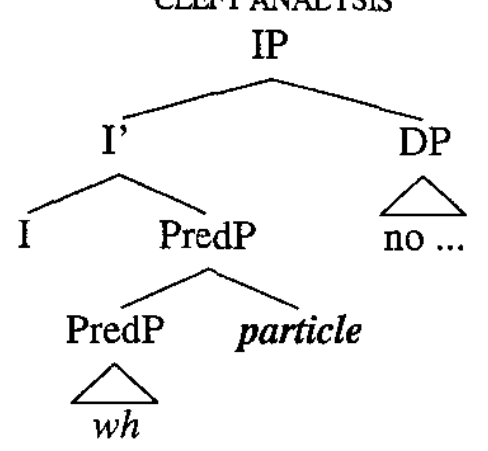

b.<smiles>CC[C+]CC</smiles>

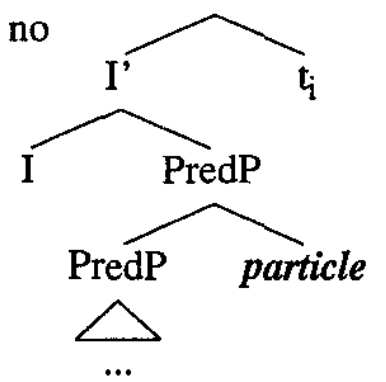

In all cases, the prediction of the cleft analysis is correct. Post-predicate particles immediately follow the wh-phrase:

(14)
a. iza (daholo) no nihinana vary (*daholo)? who all PRT eat.ACT vary all
'Who all ate rice?'
b. iza (anie) no manapaka bozaka (*anie)? who EXCL PRT cut.ACT grass EXCL
'Who is really cutting the grass?'
c. iza (foana) no mihomehy (*foana)? who always PRT laugh.ACT always 'Who is always laughing?'

Malagasy also has a number of particles that immediately precede the predicate in VOS clauses. These pre-predicate particles include toa 'seem', tokony 'should' (Paul 2001), and tena 'indeed (affirmative emphasis)':

(15) a. tokony mamangy an-dRabe Rasoa should visit.ACT ACC-Rabe Rasoa 'Rasoa should visit Rabe'
b. tena hovidin' ny zaza
EMPH buy.PASS the child
ny fiaramanidina
'The child will indeed buy the airplane'

The cleft analysis of questions correctly predicts that these particles also immediately precede the wh-phrase in a wh-question, (16). Under the fronting analysis, such data are unexpected because the wh-phrase is not a predicate and the particle should necessarily appear farther to the right. ${ }^{3}$ 
(16) a. tokony iza no mamangy an-dRabe?

should who PRT visit.ACT ACC-Rabe

'Who should visit Rabe?'

b. tena inona no hovidin' ny zaza?

EMPH what PRT buy.PASS the child

'What will the child indeed buy?'

One might object that these particles are not pre-predicate particles but clause-initial particles. If that were the correct description, then the fronting analysis would also account for the above data. There is evidence however that the particles do not simply occur clause-initially. There is a topicalization construction in Malagasy in which a constituent is preposed, followed by the topic particle dia (Keenan 1976):
a. Rasoa dia manoroka an-dRabe
Rasoa TOPIC kiss ACC-Rabe
'Rasoa, she kisses Rabe'

Paul 2001 and Flegg 2003 suggest that the initial constituent in this construction is not a predicate and, indeed, the pre-predicate particles do not occur clause-initial, but predicate-initial, in this construction, (18). ${ }^{4}$

(18) a. (*tokony) Rasoa dia (tokony) manoroka an-dRabe should Rasoa TOPIC should kiss ACC-Rabe

'Rasoa, she should kiss Rabe'

b. (*tena) ny fiaramanidina dia (tena) hovidin' ny zaza EMPH the airplane TOPIC EMPH buy.PASS the child

'The airplane, the child will indeed buy it'

In summary, the fronting analysis does not allow the grammatical placement of a wide variety of clause-internal particles, while the cleft analysis does. The whphrase in a wh-question behaves like a predicate with respect to the position of these particles, as predicted by the cleft analysis.

\section{3 multiple wh-questions}

The final argument for the cleft analysis comes from a consideration of multiple whquestions introduced in Sabel 2003, (19), in which there are two wh-phrases at the front of the clause. ${ }^{6}$ I will claim that the cleft analysis provides a better account of such data. To see this we need to lay out how each hypothesis would handle such data. I then provide arguments in favor of the cleft-based approach.

(19) a. aiza iza no mividy ny vary? where who PRT buy.ACT the rice

'Who buys rice where?'

b. aiza (ny) inona no vidinao?

where the what PRT buy.PASs.2SG

'What do you buy where?' 


\subsubsection{Sabel's (2003) fronting analysis}

Sabel 2003 proposes a clever analysis of the multiple wh-question examples within the fronting approach. That work argues that Malagasy is an optional multiple whfronting language like some of the Slavic languages. In such languages, all whphrases move to clause-initial position as in the Bulgarian data in (20) (Rudin 1988, Pesetsky 2000, Boskovic 2002, Richards 2002, and references therein).

(20) a. koj kakvo na kogo dade? who what to whom gave 'Who gave what to whom?'

b. *koj dade kakvo na kogo? who gave what to whom

Pesetsky 2000:19

Rudin 1988 first argued that there are two types of multiple wh-fronting languages. In Polish/Serbo-Croatian type languages, fronted wh-phrases move to separate CP specifiers. In Romanian/Bulgarian type languages, the fronted wh-phrases move to a single spec,C, where they form a constituent. Sabel 2003 proposes that Malagasy is of this latter type. The structure of the multiple wh-question in (19a) is (21).

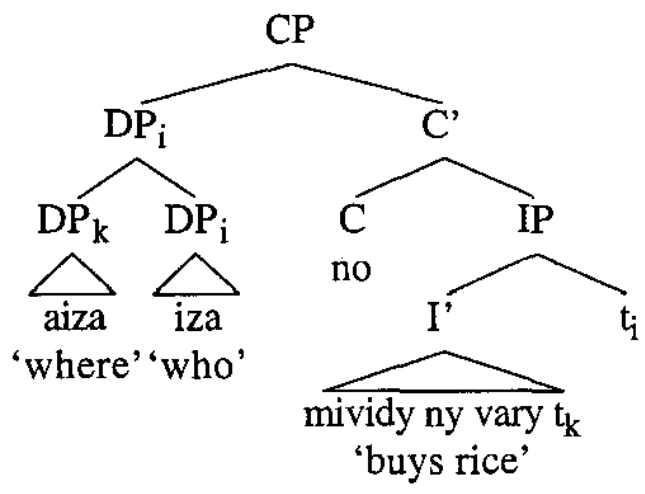

\subsubsection{Paul's (2003a) cleft analysis}

Paul 2003a indirectly provides an alternative analysis of the multiple wh-questions within the cleft approach. The analysis rests on the existence of another construction in Malagasy which Keenan 1976 called the BODYGUARD CONSTRUCTION. Keenan 1976 first observed that when a non-subject is questioned or focused, the subject may optionally appear immediately after the wh-phrase/focus, and before $n o$. The subject serves as a "bodyguard" for the fronted element. (22b) illustrates the bodyguard variant of the wh-question in (22a) and (23b) illustrates the bodyguard variant of the focus construction in (23a). The bodyguard construction is only possible when the first $\mathrm{XP}$ is an adjunct and the second $\mathrm{XP}$ is the subject.
a. aiza
no mividy
mofo
Rasoa?
where
PRT buy.ACT
bread
b. aiza
Rasoa no mividy
mofo?
where
Rasoa
PRT buy.ACT
bread
'Where does Rasoa buy bread?' 
(23)
a. omaly
no nividy yesterday
PRT buy.ACT
vary
Rabe
b. omaly
Rabe
no nividy
rice
Rabe
yesterday
Rabe
PRT buy.ACT rice
'It was yesterday that Rabe bought rice'

Paul 2003a analyzes the bodyguard construction, arguing that the bodyguard phrase is in the specifier position of the DP subject. It is a kind of possessor. This correctly places the bodyguard between the focus and the particle no. To the focus construction with bodyguard in (23b) Paul assigns the structure in (24).

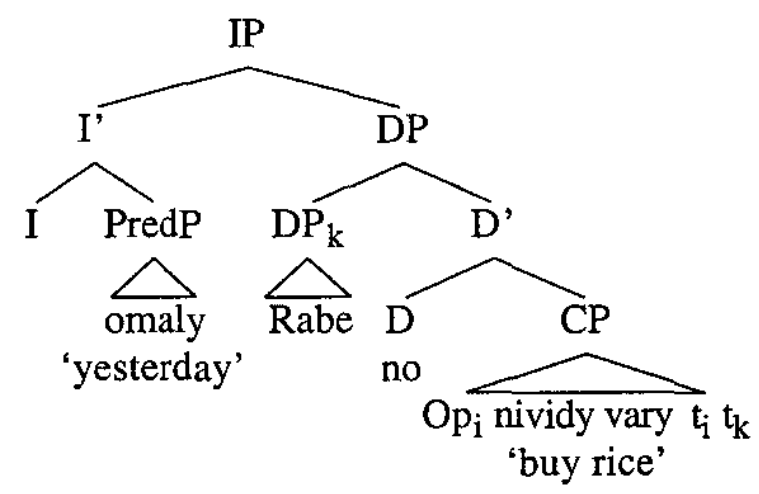

Given Paul's (2003a) analysis, we have a natural account of the multiple whquestions. They are wh-questions in which the bodyguard in spec,D is also a whphrase:

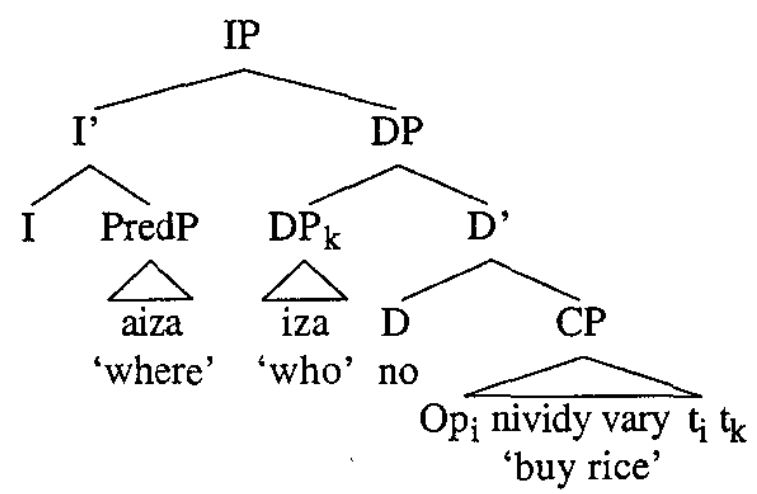

\subsection{3 arguments against the fronting analysis of multiple wh-questions}

In this subsection I present four arguments favoring the cleft treatment of the bodyguard construction and multiple wh-questions.

The first argument comes from a consideration of the ordering of the initial phrases and superiority. Pesetsky 2000 and Boskovic 2002, following Rudin 1988, show that Bulgarian multiple wh-fronting examples exhibit Superiority effects. The wh-phrase that originates structurally higher must appear before the wh-phrase that originates structurally lower: 
(26) a. koj ku de udari Ivan?

Pesetsky 2000:22

who where hit Ivan

'Who hit Ivan where?'

b. *ku de koj udari Ivan

where who hit Ivan

(*'Where did who hit Ivan?’)

Sabel 2003 shows that Malagasy patterns with Bulgarian in restricting the order of fronted multiple wh-phrases, (27).

(27) a. aiza iza no mividy ny vary?
where who PRT buy.ACT the rice
'Who buys rice where?'
b. *iza aiza no mividy ny vary?
who where PRT buy.ACT the rice
(*'Where does who buy rice?')

Sabel 2003:245

There is a difference between the two languages, however, in that they show the opposite licit orderings. In Bulgarian we see who where but in Malagasy we see where who. The question that arises under the fronting analysis is why Malagasy shows anti-superiority. Given that the wh-phrases constitute a constituent, under the fronting analysis, it must be the case that constituent formation in spec, $\mathrm{C}$ proceeds via left adjunction in Malagasy but right adjunction in Bulgarian. The theory-internal issue is how to capture this parametric variation. It can be stipulated, of course, but this is unsatisfactory and I see no principled explanation. Under the cleft analysis, by contrast, the correct ordering in (27a) is fixed by the phrase structure. The bodyguard must be a subject and it must follow the adjunct wh-predicate.

A second argument for the cleft analysis of multiple wh-questions comes from examples with multiple fronted wh-adjuncts. We have already seen that whquestions in Malagasy are sharply restricted: only subjects and certain adjuncts may be preposed. When one of each fronts, the subject must be rightmost. Even taking these restrictions into account, if Malagasy is a multiple wh-fronting language, it should still be acceptable to front other combinations of wh-phrases, specifically, two wh-adverbials. This is not possible however, regardless of whether or not a subject bodyguard is present:

(28) a. *taiza oviana no nividy mofo Rasoa?
where when PRT buy.ACT bread Rasoa
b. *oviana taiza no nividy mofo Rasoa?
when where PRT buy.ACT bread Rasoa
c. *oviana taiza Rasoa no nividy mofo?
when where Rasoa PRT buy.ACT bread
('Where did Rasoa buy bread when?')

By contrast, true multiple wh-fronting languages like Bulgarian, allow multiple adjunct questions: ${ }^{7}$ 
koga kưde jade Ana

when where eat Ana

'When did Ana eat where?'

This lack of parallelism between Malagasy and Bulgarian is surprising if the two are analytically the same kind multiple wh-fronting language. If there is a well-formed derivation for (29), it is unclear why there is not also one for (28). The pseudocleft analysis, in contrast, explains (28). The sentences cannot be generated since the second wh-adverbial can be neither a second wh-predicate nor a bodyguard.

The third problem for the fronting analysis comes from a consideration of the discourse status of the bodyguard when it is not a wh-phrase. Paul 2003a shows that the bodyguard is not part of the focus but, rather, is topical. As such, the bodyguard must be definite, (30), it cannot be the answer to an information question, (31), and it is a preferential position for pronouns.

$$
\begin{aligned}
& \text { tany an-tokotany *(ny) zazavavy no nilalao baolina Paul 2003a } \\
& \text { there ACC-yard the girl PRT play.ACT ball } \\
& \text { 'It was in the yard that the girls were playing ball' }
\end{aligned}
$$

$$
\begin{aligned}
& \text { a. iza no nanapaka bozaka oviana? } \\
& \text { who PRT cut.ACT grass when } \\
& \text { 'Who cut grass when?' } \\
& \text { b. \#omaly Rasoa no nanapaka bozaka } \\
& \text { yesterday Rasoa PRT cut grass } \\
& \text { 'It was Rasoa who cut grass yesterday' }
\end{aligned}
$$

Paul 2003a

This observation is not compatible with the fronting analysis in which the bodyguard is part of the focus in spec,C. Under the cleft analysis, the bodyguard is not part of the predicate focus; it is part of the subject topic and has a uniform derivation and discourse status. ${ }^{8}$

Fourth, there is constituency evidence against the claim of the fronting analysis that the two initial elements form a constituent, as schematized in (32a). Data below will support the pseudocleft analysis, in which the wh-phrase and the bodyguard do not form a constituent, (32b).

(32) a. [CP [WH-PHRASE BODYGUARD] [C, no VP] ]

b. [IP [VP WH-PHRASE] [DP BODYGUARD no VP] ]

FRONTING ANALYSIS

CLEFT ANALYSIS

First, (33) shows that the predicate plus bodyguard can be interrupted by the matrix clause level parenthetical hono 'so they say'.

$$
\begin{aligned}
& \text { oviana hono Rasoa/iza no nividy mofo? } \\
& \text { when PAREN Rasoa/who PRT buy bread } \\
& \text { 'When, do they say, did Rasoa/who buy bread?' }
\end{aligned}
$$


The ability of a parenthetical to appear between the wh-phrase and the bodyguard is surprising under the fronting analysis. With the pseudocleft analysis, there is a major constituent break between the predicate and the subject where the parenthetical is and (33) is expected to be grammatical.

Second, coordination facts lead to the same conclusion. The bodyguard and following material can be coordinated to the exclusion of the initial wh-phrase:

$$
\begin{array}{lllll}
\text { oviana Rasoa no nijinja vary ary Rabe no nanapaka } & \text { bozaka? } \\
\text { when Rasoa PRTharvest rice and Rabe PRT cut } & \text { grass }
\end{array}
$$

'When did Rasoa harvest rice and Rabe cut grass?'

Such examples are straightforwardly accounted for with the pseudocleft structure since the coordinated material is a constituent, as reflected in (32b). Under the fronting analysis however, there is no constituent being coordinated, see (32a), and the result should be ungrammatical, assuming that only constituents can coordinate. Further, the fronting analysis predicts that one should be able to coordinate the whphrase+bodyguard to the exclusion of no and the remaining material. This is completely impossible:

$$
\begin{aligned}
& \text { *[oviana Rabe] sy/ary [taiza Rasoa] no nividy mofo? } \\
& \text { when Rabe and where Rasoa PRT buy } \\
& \text { ('When did Rabe buy bread and where did Rasoa buy bread?') }
\end{aligned}
$$

Third, post-predicate particles treat the initial wh-phrase structurally separate from the bodyguard. When both are present, the particle follows the wh-phrase, not the bodyguard:

$$
\begin{array}{llllll}
\text { oviana (anie) Rasoa } & \text { (*anie) } & \text { no } & \text { nanapaka } & \text { bozaka? } \\
\text { when EXCL Rasoa EXCL PRT } & \text { cut } & \text { grass } \\
\text { 'When really did Rasoa cut the grass?' } & &
\end{array}
$$

In conclusion, there is good empirical evidence that Paul is correct in proposing the general structures in (24) and (25) for the bodyguard construction and, by extension, multiple wh-questions. The bodyguard is part of the subject constituent and not the predicate. No operation treats the two initial phrases as a constituent, contra the fronting analysis but in line with the pseudocleft analysis.

\section{$5 \quad$ Summary}

This paper has argued that wh-questions in Malagasy have a pseudocleft structure in which the initial wh-phrase is the predicate and the remaining material, a DP, is the subject. Despite superficial appearances, wh-questions in Malagasy are not derived by wh-movement. The cleft structure for wh-questions in Malagasy is superior in uniting the analysis of wh-questions and the focus construction, in predicting the position of predicate-related particles in wh-questions, and in providing an analysis of multiple wh-questions and the bodyguard construction. 
At this stage, a number of more detailed analytical questions arise. Two in particular are, what is the proper treatment of the particle no and why does Malagasy not appear to have any overt $\mathrm{A}^{\prime}$-movement under the adopted conception of clause structure? Is the latter an accidental observation or artifact of the simple clause structure assumed or is it some deeper property of the Malagasy grammar. I leave these and other questions for future investigation.

\section{Endnotes}

ACKNOWLEDGMENT: I would like to thank Charlotte Abel-Ratovo, Tina Boltz, Noro Brady, Hasina Randriamihamina, and Annie Rasoanaivo for the language consultations. All data are from my own notes unless otherwise indicated. Thanks also to an anonymous AFLA abstract reviewer, the audience at AFLA XI, Maria Polinsky, and Joachim Sabel. This work is supported by NSF grant BCS-0131993.

1. I use the following abbreviations in glossing: $1 / 2 / 3$-person, ACC-accusative, ACTactive voice, CIRC-circumstantial voice, EXCL-exclamative, EMPH-emphatic, NEGnegative, PAREN-parenthetical, PASS-passive voice, PRT-particle, SG/PL-number.

2. There is considerable debate as to whether the clause-final DP is a subject or an $\mathrm{A}^{\prime}$ topic-like element. I continue to refer to it as a subject for convenience, without taking a stand on the issue. See Pearson, to appear for discussion.

3. The pre-predicate particles may also appear farther to the right, (i). This is expected under both analyses however because the verb constitutes a predicate under both analyses. Such examples do not help to differentiate the two analyses.

(i) a. iza no tokony mamangy an-dRabe

who PRT should visit.ACT ACC-Rabe

'Who should visit Rabe?'

4. One unexpected piece of data in this realm concerns the negative particle $t s y$ which also occurs predicate-initial. It occurs before the VP in VOS clauses, (ia), and it may occur before the XP predicate in the focus construction, (ib).

(i) a. tsy nihinana ny vary Rasoa

NEG eat the rice Rasoa

'Rasoa didn't eat the rice'

b. tsy Rasoa no nihinana ny vary

NEG Rasoa PRT eat the rice

'It isn't Rasoa who ate the rice'

Perhaps surprisingly, negation cannot precede a wh-phrase in a wh-question, (iia). The negation must occur before the verbal predicate, (iib).

(ii) a. *tsy iza no nihinana ny vary?
NEG who PRT eat
('Who didn't eat the rice?') 

b. iza no tsy nihinana ny vary?
who PRT NEG eat the rice
'Who didn't eat the rice?

While I don't have a full explanation for the ungrammaticality of (iia), I believe that it is semantic in nature. The corresponding English cleft is also ill-formed: *Who isn't it who ate the rice? While there does not seem to be anything syntactically wrong with the English cleft, it is nonetheless unacceptable. A full explanation however must await further work.

5. The focus construction shows the same predicate behavior of the initial constituent with respect to particle placement (see Paul 2001). Post-predicate particles immediately follow the focused element and pre-predicate particles immediately precede the initial element. This further illustrates the parallel between the focus construction and wh-questions appealed to in section 4.1.

6. My consultants did not accept such examples. I am grateful to Joachim Sabel and Elisabeth Ravaoarimalala for help with the additional multiple wh-examples.

7. Thanks to Veronica Gerassimova and Maria Jordan for help with the relevant data.

8. Given the topic status of the bodyguard, Sabel's (2003) multiple wh-question examples are perhaps unexpected since the wh-phrase bodyguard does not seem to have topic properties under the given translation. The optional presence of the determiner in (19b) does suggest however that the wh-phrase bodyguard is somehow familiar. I leave for future work whether it is more appropriate to translate the bodyguard with a topic-like, d-linked wh-phrase such as which person.

\section{References}

Aldridge, Edith. 2002. Nominalization and wh-movement in Seediq and Tagalog. Language and Linguistics 3, 393-427.

Bowers, John. 1993. The syntax of predication. Linguistic Inquiry 24, 591-656.

Boskovic, Zeljko. 2002. On multiple wh-fronting. Linguistic Inquiry 33, 351-383.

Chomsky, Noam. 1995. The Minimalist Program. Cambridge, Ma.: MIT Press.

Dahl, Otto Christian. 1986. Focus in Malagasy and Proto-Austronesian. In FOCAL 1, 21-45. Pacific Linguistics.

Flegg, Jill Heather. 2003. Topics and clitic left dislocation in Malagasy. Paper presented at the AFLA X, University of Hawaii.

Georgopoulos, Carol. 1991. Syntactic variables: Resumptive pronouns and A' binding in Palauan. Dordrecht: Kluwer.

Guilfoyle, Eithne, Henrietta Hung, and Lisa Travis. 1992. Spec of IP and Spec of VP: Two subjects in Austronesian languages. Natural Language and Linguistic Theory 10, 375-414.

Keenan, Edward L. 1976. Remarkable subjects in Malagasy. In C. N. Li (ed.). Subject and Topic. New York: Academic Press, 247-301. 
Keenan, Edward L. 1995. Predicate-argument structure in Malagasy. In C. S. Burgess, K. Dziwirek, and D. Gerdts (eds.). Grammatical Relations: Theoretical Approaches to Empirical Questions. Stanford: CSLI, 171-216.

MacLaughlin, Dawn. 1995. Wh-movement in Malagasy: An extraction asymmetry. In A. Akinlabi (ed.). Theoretical approaches to African linguistics. Trenton, NJ: Africa World Press, 117-128.

Paul, Mleana. 2000. Malagasy clause Structure. Doctoral dissertation, McGill Univ.

Paul, Ileana. 2001. Concealed pseudo-clefts. Lingua 111, 707-727.

Paul, Ileana. 2002. On extraction asymmetries. In MIT Working Papers in Linguistics 44: The Proceedings of AFLA XIII. Cambridge, Ma.: MITWPL.

Paul, Ileana. 2003a. Multiple topics: Evidence from Malagasy. In Cornell Working Papers in Linguistics 19: The Proceedings of AFLA IX. Ithaca, NY: CLC Publications.

Paul, Ileana. 2003b. On the lack of wh-movement in Malagasy. Paper presented at AFLA X, University of Hawaii.

Pearson, Matthew. 1998. Rightward object shift and the syntax of adverbs. In Ileana Paul (ed.). UCLA Occasional Papers in Linguistics 20: The Structure of Malagasy II. Los Angeles: UCLA Department of Linguistics, 34-49.

Pearson, Matthew. 2001. The Clause Structure of Malagasy: A Minimalist Approach. Doctoral dissertation, UCLA.

Pearson, to appear. The Malagasy subject/topic as an A'-element. Natural Language and Linguistic Theory.

Pesetsky, David. 2000. Phrasal movement and its kin. Cambridge, Ma.: MIT Press.

Rabenilaina, Roger-Bruno. 1998. Voice and diathesis in Malagasy: An overview. In UCLA Occasional Papers in Linguistics 20: The Structure of Malagasy II, ed. by Ileana Paul, 2-10. Los Angeles: UCLA Department of Linguistics.

Rackowski, Andrea. 1998. Malagasy adverbs. In Ileana Paul (ed.). UCLA Occasional Papers in Linguistics 20: The Structure of Malagasy II. Los Angeles: UCLA Department of Linguistics, 11-33.

Richards, Norvin. 2002. Movement in Language. Oxford: Oxford University Press.

Rudin, Catherine. 1988. On multiple wh-questions and multiple wh-fronting. Natural Language and Linguistic Theory 6, 445-501.

Sabel, Joachim. 2002. Wh-questions and extraction asymmetries in Malagasy. MIT Working Papers in Linguistics 44: The Proceedings of the Eighth Austronesian Formal Linguistics Association. Cambridge, Ma.: MITWPL.

Sabel, Joachim. 2003. Malagasy as an optional multiple wh-fronting language. In Multiple wh-fronting, ed. by Cedric Boeckx and Kleanthes Grohmann, 229254. Amsterdam: John Benjamins.

Eric Potsdam

University of Florida

P.O. Box 115454

Gainesville, Florida 32611

United States

potsdam@ufl.edu 